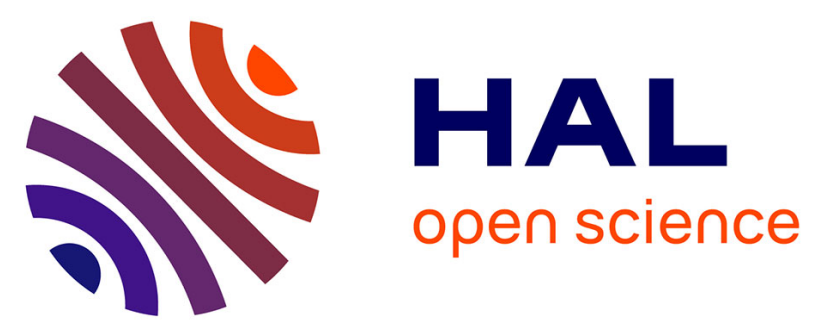

\title{
Lymphatic venous anastomosis (LVA) for treatment of secondary arm lymphedema. A prospective study of 11 LVA procedures in 10 patients with breast cancer related lymphedema and a critical review of the literature
}

\author{
R. J. Damstra, H. G. J. Voesten, W. D. Schelven, B. Lei
}

\section{- To cite this version:}

R. J. Damstra, H. G. J. Voesten, W. D. Schelven, B. Lei. Lymphatic venous anastomosis (LVA) for treatment of secondary arm lymphedema. A prospective study of 11 LVA procedures in 10 patients with breast cancer related lymphedema and a critical review of the literature. Breast Cancer Research and Treatment, 2008, 113 (2), pp.199-206. 10.1007/s10549-008-9932-5 . hal-00478313

\section{HAL Id: hal-00478313 \\ https://hal.science/hal-00478313}

Submitted on 30 Apr 2010

HAL is a multi-disciplinary open access archive for the deposit and dissemination of scientific research documents, whether they are published or not. The documents may come from teaching and research institutions in France or abroad, or from public or private research centers.
L'archive ouverte pluridisciplinaire HAL, est destinée au dépôt et à la diffusion de documents scientifiques de niveau recherche, publiés ou non, émanant des établissements d'enseignement et de recherche français ou étrangers, des laboratoires publics ou privés. 


\title{
Lymphatic venous anastomosis (LVA) for treatment of secondary arm lymphedema. A prospective study of $11 \mathrm{LVA}$ procedures in 10 patients with breast cancer related lymphedema and a critical review of the literature
}

\author{
R. J. Damstra • H. G. J. Voesten · \\ W. D. van Schelven · B. van der Lei
}

Received: 3 January 2008/Accepted: 29 January 2008/Published online: 13 February 2008

(C) Springer Science+Business Media, LLC. 2008

\begin{abstract}
Objective The incidence of breast cancer related lymphedema (BCRL) varies between 7-35\% depending on the combination of treatment modalities. Early detection of BCRL is crucial in order to start an effective non-operative treatment program. Because of the lack of prospective research on this topic, this study was undertaken to prospectively determine the effect of Lympho Venous Anastomosis (LVA) on BCRL and to review the current literature. Study design and methods Ten patients who were previously treated for breast cancer by surgery, radiotherapy, and chemotherapy, and were unresponsive to 12-weeks of non-operative treatment, underwent an LVA procedure (Degni-Cordeiro). Objective measurements were gathered for circumferential measurement and water volumetry, and quality of life. Various types of lymphoscintigraphy were carried out pre-operatively and post-operatively at 3 and 12 months. Treatment was embedded in a multidisciplinary setting. Results Post-operative volume measurements initially showed a $4.8 \%$ reduction of lymphedema at 3 months
\end{abstract}

\section{R. J. Damstra ( $\square)$}

Department of Dermatology, Phlebology and Lymphology,

Nij Smellinghe Hospital, Compagnonsplein 1,

9202 NN Drachten, The Netherlands

e-mail: r.damstra@nijsmellinghe.nl

\section{H. G. J. Voesten}

Department of Surgery, Nij Smellinghe Hospital,

Drachten, The Netherlands

W. D. van Schelven

Department of Nuclear Medicine, Medical Centre Leeuwarden, Leeuwarden, The Netherlands

B. van der Lei

Department of Plastic Reconstructive, Aesthetic and Hand Surgery, University Medical Centre Groningen, Groningen, The Netherlands and a $2 \%$ reduction after one year. Various scintigraphic parameters showed some improvement. Quality of life questionnaires reported minimal improvement. Reviewing the literature, only retrospective studies were found; these reported varying results for LVA procedures. The selection of patients, classification of lymphedema, indications and types of LVA, and additional therapeutic options were heterogeneous, not comparable, and lacked a validated method of effect-assessment. Conclusions Our results showed a minimal reduction in volume of lymphedema following LVA; in the literature, there was no convincing evidence of the success of LVA. Non-operative treatment and elastic stockings are still preferred by most patients with lymphedema, especially in early stages with few irreversible changes.

Keywords Lympho-venous anastomosis (LVA) .

Microsurgery $\cdot$ Evidence-based medicine .

Lymphoscintigraphy · Inverse water volumetry ·

Review - Breast cancer related lymphedema

\section{Introduction}

Lymphedema is a chronic disease caused by impairment of the lymphatic transport capacity, resulting in edema, excess of tissue proteins, and in latter stages, inflammation and irreversible changes such as fibrosis and excess of adipose tissue [1]. Lymph transport impairment and clinical signs of lymphedema can be acquired (secondary) or congenital (primary). Treatment of lymphedema is challenging. Therapeutic approaches consist of both non-operative and operative methods. The overwhelming majority of patients can effectively be treated by non-operative means such as complex decongestive therapy (CDT) in combination with 
manual lymphatic drainage, bandaging, physical exercises, skin care and elastic stockings. In the long lasting maintenance phase, therapeutic elastic stockings are mandatory. The goal of all non-operative treatment modalities is to reduce capillary filtration, improve drainage of interstitial fluid and macromolecules, and therefore reduce swelling, inflammation, recurrence of erysipelas, and improve quality of life [2]. Operative treatment is only indicated in a few cases as a last resort.

Many reconstructive techniques have been described, such as lymphovenous anastomosis (LVA) [3], lymphovenous-lymphatic (LVL) transplant (especially in the presence of venous hypertension [4]), and forms of lymph vessel transplantation [5]. LVA has been the most frequently used type of operation.

So far, most studies on LVA have both demonstrated a lack of significant volume reduction and considerable heterogeneity in the study populations. Therefore, we decided to evaluate the effectiveness of LVA in the treatment of one-sided breast cancer related lymphedema in a limited prospective study using objective, validated measurement methods with very strict inclusion criteria. These results will be discussed along with a review of the literature.

\section{Patients, materials and methods}

Study design and population

The study was conducted in the Lymphedema Department of Nij Smellinghe Hospital in Drachten, The Netherlands, from 1999 to 2002. A systematic review of English and German language literature retrieved from MEDLINE, COCHRANE and Cinahl databases up to April 2007 was performed. The articles were classified in levels of scientific evidence according the criteria for evidence-based medicine.

The study population consisted of 10 BCRL patients with severe lymphedema and persistent complaints, not responsive to maximal non-operative lymphedema treatment and who met the inclusion criteria for operative treatment. The patients were hospitalized in the lymphedema clinic to undergo a LVA according to our protocol.

Inclusion and exclusion criteria

In order to be included in this prospective study, patients with unilateral breast cancer related lymphedema had to meet the following criteria:

- No volume reduction after 3 months of complex decongestive treatment including manual lymph drainage, compression therapy, and physiotherapy, with persistent complaints such as heaviness, pain, shoulder function impairment, and recurrent attacks of erysipelas

- Persistent volume excess of more than $800 \mathrm{cc}$ measured by inverse water volumetry

- Proven scintigraphic signs of obstruction by absence of liver uptake and highly pathological transport index

- No recurrent malignancy

- Good patient compliance and willingness to wear therapeutic elastic stockings

- Operability.

Data collection and lymphoscintigraphy

All patients underwent objective measurements with validated methods. The quality of life was measured preoperatively and 6 months postoperatively using the validated SF-36 quality of life assessment questionnaire [6]. Volume measurements were performed prior to LVA and at 3, 6, 12, and 24 months after LVA. Volumetry was performed with the inverse water volumetry method (gold standard) [7]. Furthermore, indirect circumferential measurements were taken according the Herpertz method [8] for unilateral swelling, correlating the difference between the lymphedemic limb and the normal one.

The following clinical classification [9] (Campisi) was used:

Stage 1a: no edema, in spite of the presence of lymphatic circulation anomalies (e.g. due to mastectomy and axillary/inguinal lymphadenectomy; no difference in volume and consistency between limbs).

Stage 1b: same as stage 1a with mild edema, returning to normal after night rest.

Stage 2: permanent edema, spontaneously regressing only with antideclivous position and night rest

Stage 3: permanent edema, not spontaneously regressing with antideclivous position, and ingravescent (erysipelas/cellulitis)

Stage 4: fibrolymphedema (initial lymphostatic verrucosis) with "column" limb

Stage 5: elephantiasis with severe limb deformation (including sclero-indurative pachydermitis and lymphostatic verrucosis)

Scintigraphic protocol

Unilateral lymphoscintigraphy was performed with focus on the liver uptake. On the anterior and posterior images, 
counts were determined in the liver and in the total field of view respectively. Subsequently, geometric means were calculated for the liver and the total field of view. The liver fraction was calculated. In cases of very early detection of liver uptake, the possibility exists for technical failure resulting from unintentional intravenous injection of radioactive tracer: the fast venous transport causes the tracer to show up in the liver very early. In the case of correct subcutaneous administration of the radioactive tracer, the liver can be visualized after some time through uptake via blood vessels. The radioactive tracer reaches the blood stream either via the thoracic duct or, in the case of a functioning lymphatic venous anastomosis, via this shunt. We defined any uptake at 120 and 180 minutes as sign of lymphatic drainage from the arm, which was preoperatively absent. Results were analyzed preoperatively and one year postoperatively.

In unilateral lymphoscintigraphy, ${ }^{99 \mathrm{~m}}$ Tc-Nanocolloid was administered subcutaneously in the second interdigital space of the edematous arm. A dose of $80 \mathrm{MBq}$ and a volume of $0.1 \mathrm{ml}$ were used. Mobilization was standardized by asking the patient to make a fist repetitively during a fixed period of time. During the first 40 min following the injection, dynamic images were taken, including the entire arm, the axilla and the liver. Then images were made 60, 120 , and $180 \mathrm{~min}$ after the injection.

The images were interpreted in three ways: visual (qualitative) interpretation, semi-quantitative interpretation using the Transport Index, and quantitative interpretation through calculation of the liver fraction after 60,120 , and $180 \mathrm{~min}$.

In clinical practice, visual interpretation is the method most often used, as it is easy to perform; however, small differences between pre and postoperative studies may be difficult to recognize.

Kleinhans et al. have described the Transport Index [10]. In this index, five parameters describe the lymph flow: lymphatic transport kinetics $(\mathrm{K})$, distribution pattern (D), time lapse to appearance of lymph nodes ( $\mathrm{T}$ in minutes, multiplied by 0.04 ), assessment of lymph nodes $(\mathrm{N})$, and assessment of lymph vessels (V). Each parameter can be given a score from 0 to 9 , where 0 means that there are no abnormalities and 9 indicates that the condition for a given parameter could not be worse. The five scores are then added, resulting in the Transport Index, which can vary from 0 (normal) to 45 (most abnormal).

Operating technique

All LVA procedures were carried out under general anesthesia. A skin incision was made in the upper arm, about $7-10 \mathrm{~cm}$ above the elbow. No pneumatic tourniquet was used for exsanguination. Intradermal and subcutaneous injections of Methylene Blue were used 1 to $2 \mathrm{~cm}$ distal to the skin incision lines to outline the lymphatic system. All operative procedures were carried out by an experienced micro-vascular surgeon (BvdL) using an operating microscope. After skin incision, careful dissection was performed to identify small-sized veins (1-3 $\mathrm{mm}$ in diameter). After identifying a suitable vein, and collecting lymphatics (including some lymphatic vessels), lymphatic capillaries were dissected in the surrounding area. The diameters of these lymphatic vessels were $0.3 \mathrm{~mm}$ or less. With micro instruments, end-to-side anastomoses were made according to the Degni-Cordeiro procedure [11] using 11-0 micro sutures; at least 3-4 anastomoses were made. Average completion time of the LVA procedure was about $60 \mathrm{~min}$. Antibiotics were used perioperatively; the extremity was bandaged and elevated at night. Elastic stockings were continued permanently during the follow-up.

\section{Results}

A total of 11 LVA procedures in 10 female patients were included in our study in the period from 1998-2002. The mean age of the patients was 58.7 years $(\Delta 46-68)$. All patients had stage 3 breast cancer related lymphedema according to Campisi, and were treated with mastectomy, axillary lymph node dissection, radiotherapy, and chemotherapy. Lymphedema was present for a mean period of 5.3 years $(\Delta 3-14$ years) before LVA. None of the patients had responded sufficiently to our standardized conservative treatment program over 3 months. After removal of any pitting component, no further volume reduction could be achieved.

\section{Quality of life}

After 6 months, 5 of 10 patients had subjective relief of their complaints according to the SF-36 questionnaire.

\section{Volumetry (See also Table 1)}

After 3 months, there was a slight but insignificant reduction of volume. After one year this reduction diminished to almost zero (Table 1). The preoperative volume difference between both arms was $988 \mathrm{cc}$.

After one year, the mean volume difference was $1075 \mathrm{cc}$ ( $\Delta 500-1856)$.

The Herpertz circumferential measurement demonstrated improvement of $4.8 \%$ after one year. The initial 
Table 1 Summary of results

\begin{tabular}{|c|c|}
\hline Mean age $(n=10)$ & 58.7 Years $(\Delta 46-68)$ \\
\hline Duration of lymphedema & 5.4 years $(\Delta 3-14)$ \\
\hline Clinical classification by Campisi & Stage 3: $n=10$ \\
\hline \multicolumn{2}{|l|}{ Inverse water volumetry } \\
\hline Total volume pre OP & $4253 \mathrm{cc}(\Delta$ 2817-6456) \\
\hline Volume difference normal side pre OP & $988(\Delta 532-1400)$ \\
\hline Volume difference normal side at 3 months & $841(\Delta 232-1256)$ \\
\hline Volume difference normal side at 6 months & $994(\Delta 500-1789)$ \\
\hline Volume difference normal side at 12 months & $1075(\Delta 500-1856)$ \\
\hline \multicolumn{2}{|l|}{ Herpertz method at 0-12 months: (at four points) } \\
\hline Mean Volume difference pre OP & $35.2 \%(\Delta 20-50 \%)$ \\
\hline Mean volume difference 12 months & $33.5 \%(\Delta 18-49 \%)$ \\
\hline \multicolumn{2}{|l|}{ Visual signs lymphoscintigraphy } \\
\hline Dermal back flow & 10 \\
\hline Lymph vessels & 0 \\
\hline Lymphnode in the elbow & 1 \\
\hline \multicolumn{2}{|l|}{ Kleinhans transport index at 0-12 months } \\
\hline TI pre OP & $43.0(\Delta 28-45)$ \\
\hline TI post OP & $42.2(\Delta 30-43)$ \\
\hline \multicolumn{2}{|l|}{ Liver uptake at $0-12$ months } \\
\hline LC pre OP (after 120 and $180 \mathrm{~min}$ ) & 0 \\
\hline LC post OP (after 120 and $180 \mathrm{~min}$ ) & 0 \\
\hline SF 36 questionnaire $0-6$ months & Slight subjective improvement in 5 patients who felt less disabled \\
\hline
\end{tabular}

volume reduction with water displacement of $16 \%$ at three months was lost after one year, when no more than $2 \%$ volume difference was observed.

\section{Scintigraphy (see also Table 1)}

According to the Kleinhans transport index, there was no significant difference in transport before and one year after the operation: $43.0(\Delta 28-45)$ versus $42.2(\Delta 30-43)$.

Qualitative scintigraphic observation demonstrated an absence of lymph transport, dermal backflow and few signs of any organized transport, comparable with longstanding lymph-obstruction. In one patient, a lymph node in the elbow was visualized. After one year, a quantitative scintigraphical evaluation demonstrated no liver uptake after LVA, as compared with an initial lymphoscintigraphy.

\section{Long term follow-up}

Beyond the initial study design, at long term follow up in 2007 (mean follow-up 8 years), 2 patients had stable lymphedema using elastic stockings, 3 patients had died of metastasis, 4 patients had complete volume reduction after circumferential suction-assisted lipectomy (Brörson method
[12]) and 1 patient was lost to follow up. The main characteristics and results of 10 patients are presented in Table 1.

\section{Discussion}

This prospective study clearly demonstrates that, although there was an initial period of relief of the subjective complaints in 5 of 10 patients, there were no significant improvements after LVA in our series of patients with chronic lymphedema; neither volume measurements nor scintigraphic measurements showed any effect.

When reviewing the literature of the last decades (see Table 2), there is a striking lack of prospective and comparative studies concerning the effect of LVA on chronic lymphedema. All studies reviewed initially used nonoperative treatment by CDT for a period ranging from 3 days up to 6 months. Although this might create a bias when selecting patients for LVA, the alternative is that many patients would have unnecessary operative treatment with perhaps detrimental effects. Most patients with early stages 1-3 of lymphedema can be treated successfully with CDT [22, 23]. Moreover, in many studies information is missing about the follow-up protocol and many do not report whether or not elastic stockings are mandatory after an LVA procedure. 


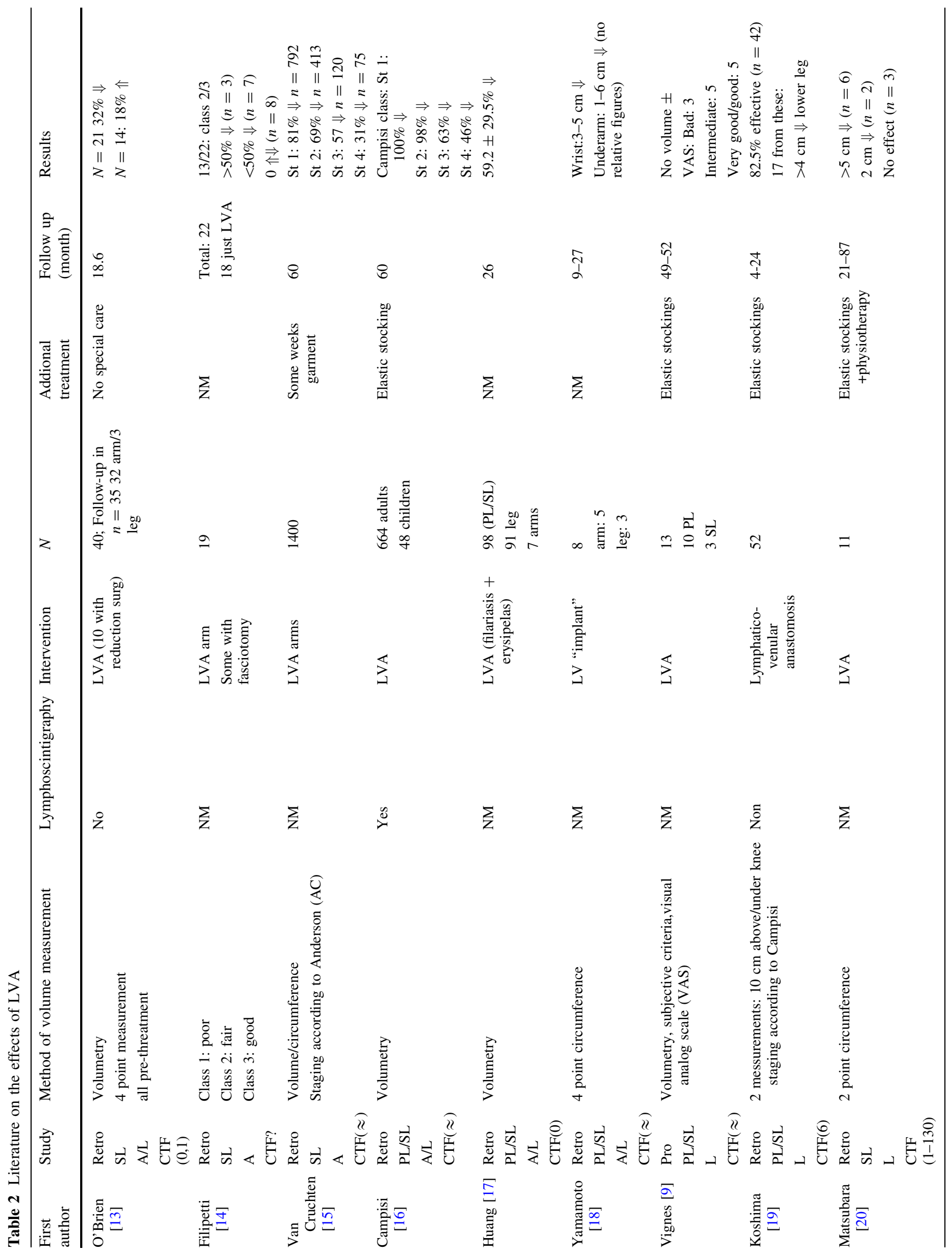




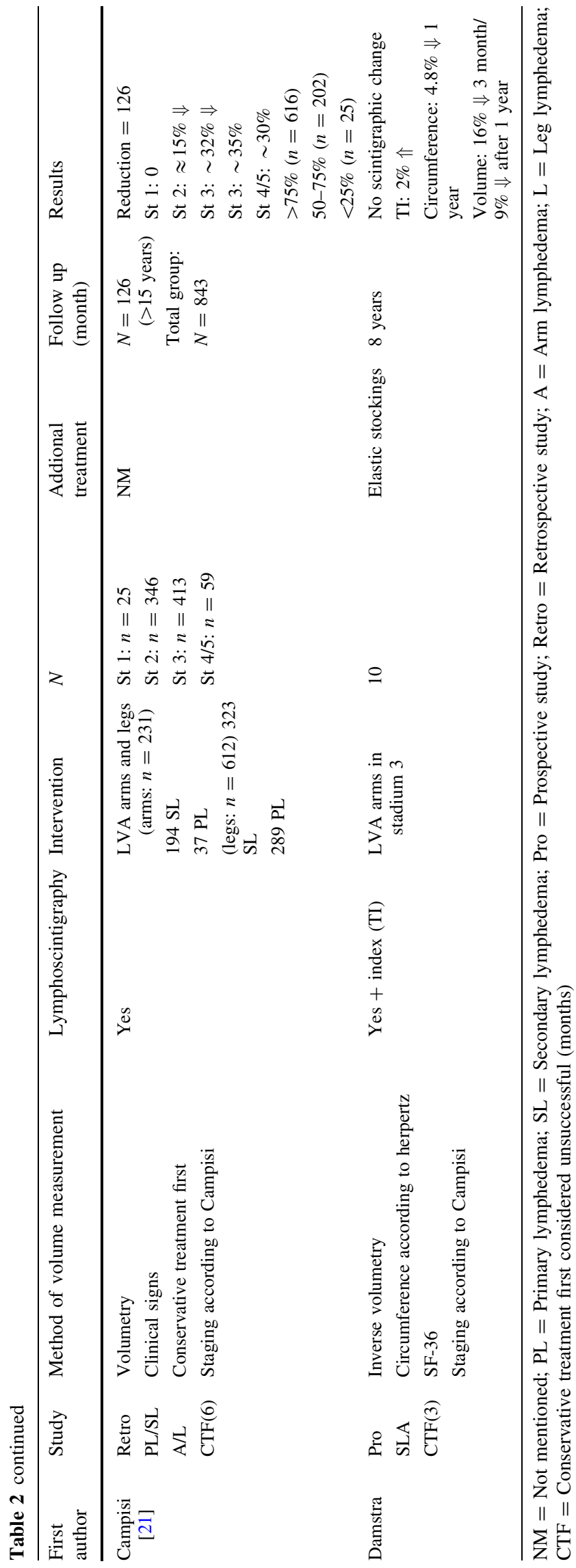

In order to compare treatment options, an adequate classification is necessary. According to stages 1 to 3 , conservative treatment of lymphedema is sufficient in most patients [22, 23]. In stage 3 lymphedema, the pitting component can often be treated successfully; however the fibrosis and access of adipose tissue will remain. Matsubara [20] studied LVA in 9 women with secondary lymphedema of the legs refractionary to non-operative management. He obtained the best results when operative procedures were combined with continued postoperative physiotherapy.

In a recent personal communication, Campisi [24] suggested that from his point of view, LVA is most suitable in the early stages $1 \mathrm{~B}$, II and early III. No other postoperative therapeutic modalities such as elastic stockings, decongestive treatment or anti platelet clotting medication were mentioned. Campisi advised initial physical treatment for peripheral lymphedema. Additionally, in later stages (3,4 and 5), in the absence of scintigraphical visualization of lymphatics, it is standard procedure to reduce the lymphedema by non-operative methods first, before considering microsurgery. According to Campisi LVA is further contra-indicated for lymphaticlymphnodal aplasia and stage 5 lymphedema.

For these stages Brorson [12] described a promising method (circumferential suction-assisted lipectomy) that introduces reductive surgical therapy with good long-term results, demonstrating more than $100 \%$ volume reduction. Elastic stockings must be worn to maintain these excellent results. From this perspective, we used this method successfully in 4 of our 10 patients refractionary to LVA.

From a pathophysiological perspective, the goal for LVA is to reduce interstitial volume by improving lymphatic drainage. To exemplify the results of LVA, we chose objective outcome parameters for improvement of lymphtransport capacity, volume changes and quality of life. Kleinhans et al. demonstrated the usefulness of the Transport Index to evaluate the results of lymphatic grafting [25-27].

In general, lymphoscintigraphy is performed bilaterally, offering objective evidence to distinguish (late stage) lymphatic pathology from non-lymphatic causes of extremity edema. Criteria for lymphatic dysfunction include delayed ( $>30 \mathrm{~min}$ ), asymmetric, or absent visualization of regional lymph nodes, and the presence of "dermal backflow". Additional findings include asymmetric visualization of lymphatic channels and collateral lymphatic channels. All of these parameters are correlated with a clinical diagnosis of lymphedema [28, 29]. Liver fraction scanning [30] is only of merit when the radionuclide is administered in the edematous extremity. Late uptake in the liver (after $3 \mathrm{~h}$ ) is an indication of lymphatic transport out of the injected arm. The theoretical advantage 
of using the liver fraction as an objective means to judge lymphovenous shunt efficacy is clear.

In the current study, we considered any uptake as a positive result. Therefore, we postulated, with an open and well functioning shunt, in due time the radionuclide would be transported from the arm via the shunt into the veins of the arm, followed by further transport to the reticuloendothelial system, which is mainly located in the liver. A perceptible liver fraction on the postoperative images, when compared to the preoperative situation, thus should indicate an open, well functioning shunt. In this study we could not find any significant improvement in the objective parameters for volume change or liver uptake of ${ }^{99 \mathrm{~m}} \mathrm{Tc}$ Nanocolloid. In the literature, convincing, validated, and objective methods for visualization of the effects of a LVA are missing.

\section{Conclusions}

In this first prospective study on the LVA treatment of unilateral breast cancer related lymphedema, despite the limited number of patients, no effect could be measured using objective validated measurement methods. The effects of LVA in literature are also not proven; there is a lack of standardization of the patient population, and the measurement methods are not validated. Most studies are retrospective and often involve a mix of primary, secondary arm and leg lymphedema in the same study. On top of this, classification of lymphedema varies, and the indications and criteria for LVA are unclear. Therefore we conclude that, considering our results and the literature review, LVA is not effective for the treatment of unilateral breast cancer related lymphedema. Although the LVA has been performed and studied for more than 3 decades, this method still has not had a breakthrough and will never become a treatment of choice in daily practice.

Non-operative, decongestive treatment combined with the regular use of elastic stockings is the corner stone of treatment for most patients with lymphedema, especially in its early stages when it involves few irreversible changes; however, in later stages with more irreversible changes, LVA still does not effectively reduce volume.

\footnotetext{
Acknowledgements Contributions R.J. Damstra was the lead author in the overall conceptualization and design of the study and the manuscript. He collected the data and prepared the databases. H.G.J Voesten participated in revising and editing the text. W.D. van Schelven participated in the design and the execution of the (semi) quantitative scintigraphic studies, as well as the analysis and the interpretation of the scans. He had the primary responsibility for the scintigraphic paragraphs. B. van de Lei performed all microsurgical procedures, participated in drafting the text and provided overall supervision of the manuscript.
}

\section{References}

1. Brorson H, Ohlin K, Olsson G, Nilsson M (2006) Adipose tissue dominates chronic arm lymphedema following breast cancer: an analysis using volume rendered CT images. Lymphat Res Biol 4(4):199-210

2. Mortimer PS (1997) Therapy approaches for lymphedoedema. Angiology 48(1):87-91

3. O'Brien BM, Sykes PJ, Threlfall GN, Browning FS (1977) Microlymphaticovenous anastomoses for obstructive lymphedema. Plast Reconstr Surg 60(2):197-211

4. Campisi C, Boccardo F, Zilli A, Maccio A (2001) the use of vein grafts in the treatment of peripheral lymphedemas: long term results. Microsusrgery 21(4):143-147

5. Baumeister RGH, Frick A (1996) Die autogen gefasstransplantation zur microchirurgischen Rekonstruktion des Lymphgefassysteems. Phlebol 25:83-88

6. Aaronson NK, Muller M, Cohen PD, Essink-Bot ML, Fekkes M, Sanderman R, Sprangers MA, te Velde A, Verrips E (1998) Translation, validation, and norming of the Dutch language version of the SF-36 health survey in community and chronic disease populations. J Clin Epidemiol 51(11):1055-1068

7. Damstra RJ, Glazenburg E, Hol W (2006) The validation of the inverse water volumetry: New gold standard for arm volume measurement. Breast Cancer Res Treat 99(3):267-273

8. Herpertz U (1994) Messung und Dokumentation von Ödemen. Lymphologie 18:24-30

9. Vignes S, Boursier v, Priollet P, Miserey G, Trévidic P (2003) Quantitative evaluation and qualitative results of surgical lymphovenous anastomosis in lower limb lymphedema. J Mal Vasc 28(1):30-35

10. Kleinhans E, Baumeister RGH, Hahn D, Siuda S, Bull U, Moser E (1985) Evaluation of transport kinetics in lymphoscintigraphy: follow-up study in patients with transplanted lymphatic vessels. Eur J Nucl Med 10:349-352

11. Degni M (1981) New techniques of lymphatic-venous anastomosis for the treatment of lymphedema. Lymphlology 14(2): $61-63$

12. Brorson H (2003) Liposuction in arm lymphedema treatment. Scand J Surg 92(4):287-295

13. O'Brien BC, Shafiroff BB (1979) Microlymphaticovenous and resectional surgery in obstructive lymphedema. World J Surg 3(1):3-15

14. Filippetti M, Santoro E, Graziano F, Petric M, Rinaldi G (1994) Modern approaches to postmastectomy brachial lymphedema. Microsurgery 15(8):604-606

15. Cruchten LH van, Nieuborg L (1995) Diagnose en behandeling van lymfoedeem. Ned Tijdschr Geneeskd 138:653-657

16. Campisi C, Boccardo F, Alitta P, Tachella M (1995) Derivative lymphatic microsurgery: indications, techniques and results. Microsurgery 16(7):463-468

17. Huang GK (1989) Ergebnisse microchirurgischer lymphvenöser Anastomosen bei Lymphödemen Bericht über 110 Fälle. Langenbecks Arch Chir 374:194-199

18. Yamamoto Y, Sugihara T (1998) Microsurgical lymphaticovenous implantaton for the treatment of chronic lymphedema. Plast Reconstr Surg 101(1):157-159

19. Koshima I, Nanba Y, Tstsuya T, Takahahi Y, itoh S, Fujitsu M (2004) Minimal invasive lymphaticovenular anastomosis under local anesthesia for leg lymphedema. Is it effective for stage III and IV?. Ann Plast Surg 53:261-266

20. Matsubara S, Sakuda H, Nakaema M, Kuniyosh Y (2006) Long term results of microscopic lymphatic vessel isolated vein anastomosis for secondary lymphedema of the lower extremities. Surg Today 36:859-864 
21. Campisi C, Davini D, Bellini C, Taddei G, Villa G, Fulcheri E, Zilli A, Da Rin E, Eretta C, Boccardo F (2006) Lymphatic microsurgery for the treatment of lymphedema. Microsurgery 26:65-69

22. Földi E, Földi M, Clodius L (1989) The lymphedema chaos: a lancet. Ann Plast Surg 22(5):148-151

23. Szuba A, Cooke JP, Youuf S, Rockson SG (2000) Decongestive lymphatic therapy for patients with cancer related or primary lymphedema. AM J Med 109:296-300

24. Campisi C, Eretta C, Pertile D, Dan Rin D, Campisi C et al (2007) Microsurgery for treatment of peripheral lymphedema: long term outcome and future perspectives. Microsurgery 27(4):333-338

25. Baumeister RG, Siuda S (1990) Treatment of lymphedemas by microsurgical lymphatic grafting: what is proved? Plast Reconstr Surg 85:64-76
26. Weiss M, Baumeister RGH, Hahn K (2002) Post-therapeutic lymphedema: scintigraphy before and after autologous lymph vessel transplantation; 8 years of long-term follow-up. Clin Nucl Med 27:788-792

27. Vaqueiro M, Gloviczki P, Fisher J, Hollier LH, Schirger A, Wahner HW (1986) Lymphoscintigraphy in lymphedema: an aid to microsurgery. J Nucl Med 27:1125-1130

28. Yuan Z, Chen L, Zhu J, Lu H, Zhu R (2006) The role of radionuclide lymphoscintigraphy in extremity lymphedema. Ann Nucl Med 20(5):341-344

29. Scarsbrook AF, Ganeshan A, Bradley KM (2007) Pearls and pitfalls of radionuclide imaging of the lymphatic system: part 2: evaluation of extremity lymphedema. Br J Radiol 80(951):219226

30. Ketterings C, Zeddeman S (1997) Use of the C-scan in evaluation of peripheral lymphedema. Lymphology 30:49-62 